\title{
THE SURVEY OF CANCER PATIENTS IN THE REGION OF GUNTUR: BASED ON HOSPITAL REGISTRY
}

\author{
D. RAVI SANKAR REDDY*, G. KALYANI ${ }^{1}$, K. PRADEEP ${ }^{2}$, MD. ASIF $^{3}$, D. KARTHEEK ${ }^{4}$, M. GANGABHAVANI ${ }^{5}$ \\ *Department of Pharmaceutical Chemistry, University College of Pharmaceutical Sciences, Acharya Nagarjuna University, Nagarjuna \\ Nagar 522510 \\ Email: gadekalyani1989@gmail.com
}

Received: 03 Nov 2016 Revised and Accepted: 21 Dec 2016

\section{ABSTRACT}

Objective: This survey was conducted to estimate the number of cancer patients in the region of Guntur-based on sex, age and cancer groups. The data were obtained from the hospital-based registries from Bommidala Cancer Institute, NRI Hospital, Balaji Cancer Care Center, and Govt. General Hospital, which was scrutinized and analysed.

Methods: The hospital registry entry was considered suitable for assessing the cancer cases in the region of Guntur. In addition, data of NCRP were utilised for comparing the obtained results.

Results: The data comprehensively constitutes of 309 patients. Out of which men were 74 (23.95\%), and women were 235 (76.05\%) who had obtained treatment for various cancer conditions between March-May, 2016. In these hospitals, cancers pertaining to the cervix-83 (31.32\%), breast-52 (19.62\%), ovary-17 (6.41\%), lymphoid-11 (4.15\%), pharynx-10 (3.77\%), endometrium-10 (3.77\%), astrocytoma-08 (3.02\%), colon-07 (2.64\%), larynx-06 (2.26\%), rectum-06 (2.26\%), oesophagus-05 (1.88\%), post cricoids-04 (1.50\%), stomach-04 (1.50\%), liver-03 (1.13\%) were the leading sites in order. While among these cases, radiation therapy patients were $194(62.78 \%)$, chemotherapy patients were $78(25.24 \%)$, and surgery patients were $37(11.97 \%)$.

Conclusion: Survey reports the highest incidence of cancer cases to be cervix cancer among the women while it was pharyngeal cancer which precedes lung cancer among the men. This hospital-based registry survey is a report that provided internal consistency, reliability and validity.

Keywords: Carcinoma, Cancer therapy, Iceberg phenomenon, National Cancer Registry Programme

(C) 2017 The Authors. Published by Innovare Academic Sciences Pvt Ltd. This is an open access article under the CC BY license (http://creativecommons.org/licenses/by/4. 0/) DOI: http://dx.doi.org/10.22159/ijpps.2017v9i2.16026

\section{INTRODUCTION}

Cancer is the major threatening disease of all time [1]. Many cases have been reported at late stages while some have been left untreated. Cancer is also known as a malignant tumor or malignant neoplasm, which is a group of diseases involving abnormal cell growth, having the potential to invade or spread into other parts of the body. Normal cells grow, divide in order, in accordance with that of the cell cycle [2]. Mutations in proto-oncogenes or in tumor suppressor genes will allow a cancerous cell to grow and divide without the normal controls of the cell cycle. The major sites of cancers in males were lungs, prostate, colorectal, and stomach. While in females, they are breast, colorectal, lung, and cervical, ovarian regions [3]. Types of Cancers based on arising cells are 1) Carcinoma 2) Sarcoma 3) Lymphoma 4) leukaemia 5) Germ cell tumor 6) Blastoma. The great majority of cancers, $90-95 \%$ of cases are due to tobacco, (25-30\%) because of obesity, (30-35\%) infections, (15-20\%) radiation, (10\%) stress, lack of physical activity and environmental pollutants. The remaining $5-10 \%$ are due to inherited genetics involving hormonal, mutational changes. Treatment methods include radiation, chemotherapy and surgical therapy.

Cancer therapy includes hormone therapy, which is usually done with drugs that block the activity of the hormone, such as that of Tamoxifen and Raloxifene. Angiostatin and Endostatin are some of the Chemotherapy compounds. Radioimmunotherapy [4], targeting specifically the cancer cells. There are two main types of cancer registry: hospital-based and population-based cancer registries. Hospital-based cancer registries are concerned with the recording of information about the cancer patients seen in a particular hospital. The main purpose of such a registries is to contribute to patient care by providing readily accessible information about the subjects with cancer, the treatment they received and its result. The data are used mainly for administrative purposes and for reviewing clinical performance.

Although these data may be used, to a certain extent, for epidemiological purposes, these registries cannot provide measures against the occurrence of cancer in a defined population because it is impossible to define their catchment populations that are the populations from which all the cases arise. However, there are many limitations for cancer screening in India [5]. Given the limitations in large-scale population-based screening programme, we have chosen the hospital-based registry entry which reports a number of cancer cases from four hospital registries of the Guntur region for selected sites in accordance with patient's age, sex, type of cancer. NCRP has published a report in cancer Incidence rate, which depicts changes in incidence rates of cancer from urban and rural registries of India [6]. However, in our survey, a similar attempt has been made to project cancer cases observed in four selected hospitals within the region of Guntur by sex, age and cancer groups.

\section{MATERIALS AND METHODS}

\section{Hospital registry survey}

Generally, disease surveys are done by population-based registry survey or hospital-based registry survey. Hospital-based cancer registries survey [7] is concerned with the recording of information about the cancer patients seen in a particular hospital as the population-based cancer registries survey seeks to collect data on all new cases of cancer occurring in a well-defined population. The hospital-based registry survey was chosen because of the drawbacks of the population-based registry survey. The hospital-based registry survey further can be used for comparison, estimation and for the elimination of the disease condition to a major extent in some of the referral hospitals [8]. 


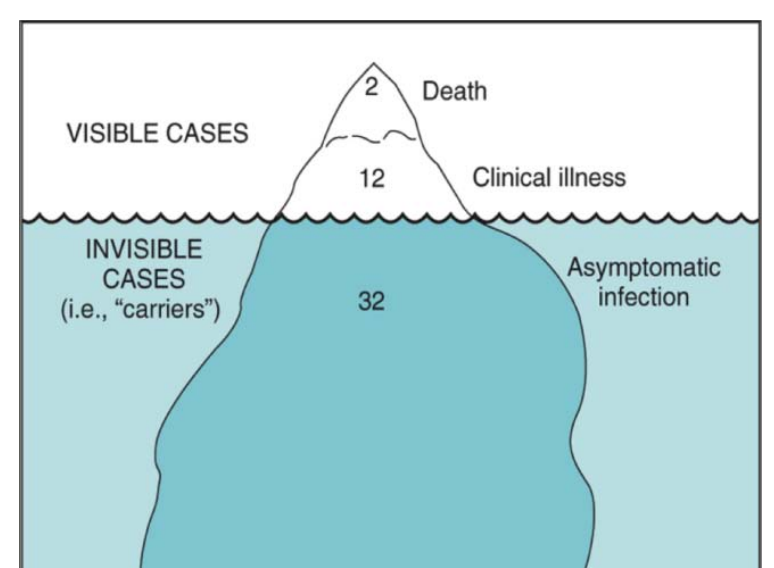

Fig. 1: Iceberg phenomenon illustration in view of diseases

Hospital-based registry survey was understood by the iceberg phenomenon [9]. The iceberg phenomenon of disease gives a picture of the spectrum of disease with in a community or society. The upper visible part of iceberg represented the clinically apparent cases of the disease in the community while the part of the iceberg below the water level denoted the latent, subclinical, undiagnosed and carrier states with in the community, which forms the major part. The hidden part is especially important in a disease like cancer. The data of various cancer cases provided with in the report were collected from four cancer centers in the region of Guntur using hospital register entries during the months of March-May, 2016.

\section{Data collection}

Cancer case registration process involved our visits to three oncology departments and one oncology centre in the Guntur district. The data were scrutinised from the medical records kept in the medical records departments as well as in individual departments concerned about the diagnosis and treatment of cancers [10]. Cancer cases diagnosed by all methods are identified and recorded. Cancer case's incident during March-May, 2016 is included in the analyses. The population at risk by sex are females while the age group 60-70 y is at risk among both the sexes. The selected cancer patient's data and the corresponding cancer sites were furnished with table 1 . The results are presented as the number of cases by site, sex, age using the hospital registry entries.

\section{RESULTS}

\section{Survey in four prospective cancer centres}

\section{Survey findings in the bommidala cancer Institute (BMCI)}

Totally 97 cancer patients were observed in BMCI from which the number of male patients was $18(16.49 \%)$ while female patients were $79(83.50 \%)$. In this hospital, cervix $(48.45 \%)$, breast (21.64\%), lung $(4.12 \%)$, endometrium $(4.12 \%)$, post-cricoid $(2.06 \%)$, larynx $(2.06 \%)$, brain $(2.06 \%)$, liver $(2.06 \%)$ were the leading sites of cancer in order. Data also provides information about cancer therapy based outcome, which includes a number of radiation therapy patients $60(61.85 \%)$, chemotherapy patients 30 $(30.92 \%)$, surgery patients $07(7.2 \%)$ respectively. The data collected from the BMCI according to age, sex and number of patients was given in table 2. From fig. 2 it was found that the majority of patients are in the age groups 60 to $70 \mathrm{y}$ of age. Least number of cases were in between 20-30 y, i.e. six members while the maximum number of cancer cases is in the age groups between 60 70 y, i.e. 28 members.

\section{Survey findings in the non-Resident Indian (NRI) hospital}

It was observed that in NRI, i.e. in the American oncology Institute hospital out of 109 cancer patients the number of male patients were 37 (33.94\%) while female patients were 72 (66.04\%). We observed one child of seven-year age, having astrocytoma. In this hospital, cervix $(14.68 \%)$, breast $(10 \%)$, post cricoids $(7.34 \%)$, ovary, astrocytoma and lymphoid (6.4\%), lung (4.12\%), colon $(3.6 \%)$, rectum $(2.4 \%)$, were the leading sites of cancer in order. Data also provides information about cancer therapy based outcome, which includes a number of radiation therapy patients 50 (45.87\%), chemotherapy patients $29(26.60 \%)$, surgery patients 30 $(27.52 \%)$ respectively. The data collected from the NRI hospital according to age, sex and number of patients is given in table 2 . From fig. 2, it was found that the majority of patients are in the age groups between 60 to $70 \mathrm{y}$ of age. Least number of cases were in between 0-10 y, i.e. one member while the maximum number of cancer cases is in the age groups between 50-60 y, i.e. 26 members.

\section{Survey findings in the Balaji cancer care (BCC)}

In BCC centre, 53 cancer patients were observed from which the number of male patients was $04(7.54 \%)$ while female patients were $49(92.45 \%)$. In this hospital, breast (22.6\%), cervix (18.87\%), ovary (15.1\%), endometrium (7.5\%), lymphoid (7.5\%), colon (5.6\%), lung $(4.12 \%)$, rectum $(1.8 \%)$, post cricoids $(1.8 \%)$, were the leading sites of cancer in order. Data also provides information about cancer therapy based outcome, which includes a number of radiation therapy patients $34(64.15 \%)$, chemotherapy patients 19 (35.85\%), surgery patients $0(0 \%)$ respectively. The data collected from the BCC according to age, sex and number of patients is given in table 2 . From fig. 2 it was found that the majority of patients are in the age groups between 60 to $70 \mathrm{y}$ of age. Least number of cases are in the age groups between 20-30 y, i.e. two members while the maximum number of cancer cases is in the age groups between $40-50$ y, i.e. 16 members.

\section{Survey findings in government general hospital (GGH)}

It was observed that in government general hospital (GGH) 50 cancer patients were observed from which the number of male patients was $18(36 \%)$ while female patients were $32(64 \%)$. In this hospital, cervix $(24 \%)$, breast $(16 \%)$, pharynx and tongue cancer $(10 \%)$, oesophagus (8\%), vault (6\%), ovary (4\%), larynx (4\%), colon $(2 \%)$, rectum $(2 \%)$, post cricoids $(2 \%)$, were the leading sites of cancer in order. Data also provides information about cancer therapy based outcome which includes a number of radiation therapy patients $50(100 \%)$, chemotherapy patients $0(0 \%)$, surgery patients $0(0 \%)$ respectively. The data collected from the GGH according to age, sex and number of patients is given in table 2 . From fig. 2 least number of cancer cases were found in the age groups between 0-30 y, i.e. one member while the maximum number of cases are in the age groups between $60-70$ y, i.e. 14 members.

\section{Consolidated report}

The Cancer sites along with the number of patients with respect the sex, age in accordance with each of the four hospitals was confined, and the results were executed in correlation to each other. The overall report of the cancer data collected from all four hospitals comprehensively constitutes of 309 patients. The data were observed and collected according to the age, type of cancer, treatment method and sex as of the patient. From fig. 3, it was observed that a number of male patients were 74 (23.95\%) while female patients were $235(76.05 \%)$. In these hospitals, cervix cancer-83 (31.32\%), breast cancer [9]-52 (19.62\%), ovary cancer$17(6.41 \%)$, lymphoid-11 (4.15\%), pharynx-10 (3.77\%), endometrium-10 (3.77\%), astrocytoma-08 (3.02\%), tongue cancer07 , vault- 07 and colon cancer-07 (2.64\%), larynx cancer-06 (2.26\%), rectum-06 (2.26\%). lung and oesophagus-05 (1.88\%), post cricoids-04 (1.50\%), stomach-04 (1.50\%), liver-03 (1.13\%) were the leading sites in order. Data also provides information about cancer therapy based outcome, which includes a number of radiation therapy patients $194(62.78 \%)$, chemotherapy patients 78 (25.24\%), surgery patients $37(11.97 \%)$ respectively. From fig. 4 it was observed that a major number of patients were in age groups between 60 to $70 \mathrm{y}$, and the cancer attacks were more frequent in the age groups between $30-70 \mathrm{y}$.

\section{Comparative study}

The present survey results are compared to that of the National Cancer Registry Programme (NCRP) results [11] which were 
demonstrated in the fig. 5. In NCRP results, more number of patients were suffering with cervix cancer while the present survey also reveals that the more number of patients were suffering with cervix cancer [12] in the four consecutive hospitals. In addition, the second major number of patients were suffering with breast cancer, which is same to that of the NCRP [13] data.

There are varied approaches to identify the cancer cases using the registry data [14]. Many authors have used age, sex, and some other factors to arrive at cancer cohort studies. However, while studying the trends in NCRP with that of the survey data [15], it was observed few sites of cancer do exhibit inconsistent changes like sites of Mouth, vault, Esophageal, Colon cancers. The survey data revealed some major cancers prevailing in the region of Guntur, which are arranged in the descending order of the number of patients as follows as in the fig. 5. They are characterised by an increase or decrease in numbers with respect to the hospital. Hence, for the present paper, the present cases have been assessed to compile the data. Tobacco is the most important identified cause of cancer and is responsible for $30-50 \%$ of cancers in men while it is $10-15 \%$ in women as per NCRP-2008 data.

Table 1: Prominent cancer sites observed in the survey among the four hospitals

\begin{tabular}{|c|c|c|c|}
\hline $\begin{array}{l}\text { S. } \\
\text { No. }\end{array}$ & Hospital name & $\begin{array}{l}\text { Number of } \\
\text { patients }\end{array}$ & Cancer sites \\
\hline 1 & Bommidala cancer institute (BMCI) & 97 & Cervix, Breast, Lung, Endometrium, Post cricoids, Larynx, Brain, Liver \\
\hline 2 & Non-Resident Indian Hospital (NRI) & 108 & Cervix, Breast, Post cricoids, Ovary, Astrocytoma, Lymphoid, Lung, Colon, Rectum \\
\hline 3 & Balaji cancer care centre (BCC) & 53 & Breast, Cervix, Ovary, Endometrium, Lymphoid, Colon, Lung, Rectum, Post cricoids \\
\hline 4 & Government general hospital (GGH) & 51 & $\begin{array}{l}\text { Cervix, Breast, Pharynx, Tongue, Cancer, Esophagus, Vault, Ovary, Larynx, Colon, } \\
\text { Rectum, Post cricoids }\end{array}$ \\
\hline
\end{tabular}

Table 2: Data representation in all four consecutive hospitals

\begin{tabular}{|c|c|c|c|c|c|c|c|c|c|c|c|c|c|c|}
\hline \multirow[t]{2}{*}{$\begin{array}{l}\text { S. } \\
\text { No. }\end{array}$} & \multirow[t]{2}{*}{ Age } & \multicolumn{3}{|c|}{$\begin{array}{l}\text { Non Resident Indian } \\
\text { hospital }\end{array}$} & \multicolumn{3}{|c|}{ Bommidala cancer institute } & \multicolumn{3}{|c|}{ Balaji cancer care center } & \multicolumn{3}{|c|}{$\begin{array}{l}\text { Government general } \\
\text { hospital }\end{array}$} & \multirow{2}{*}{$\begin{array}{l}\begin{array}{l}\text { Over all } \\
\text { total } \\
\text { number of } \\
\text { patients }\end{array} \\
\end{array}$} \\
\hline & & Male & Female & $\begin{array}{l}\text { Total } \\
\text { Number } \\
\text { of } \\
\text { patients }\end{array}$ & Male & Female & $\begin{array}{l}\text { Total } \\
\text { Number of } \\
\text { patients }\end{array}$ & Male & Female & $\begin{array}{l}\text { Total } \\
\text { Number } \\
\text { ofpatient } \\
\text { s }\end{array}$ & Male & Female & $\begin{array}{l}\text { Total } \\
\text { Number } \\
\text { of } \\
\text { patients }\end{array}$ & \\
\hline 1 & $0-10$ & 01 & 00 & 01 & 00 & 00 & 00 & 00 & 00 & 00 & 00 & 01 & 01 & 02 \\
\hline 2 & $10-20$ & 02 & 00 & 02 & 00 & 00 & 00 & 00 & 00 & 00 & 00 & 01 & 01 & 03 \\
\hline 3 & $20-30$ & 03 & 05 & 08 & 03 & 03 & 06 & 00 & 02 & 02 & 00 & 01 & 01 & 17 \\
\hline 4 & $30-40$ & 07 & 21 & 28 & 01 & 15 & 16 & 01 & 09 & 10 & 03 & 05 & 08 & 62 \\
\hline 5 & $40-50$ & 05 & 20 & 25 & 01 & 17 & 18 & 02 & 14 & 16 & 02 & 08 & 10 & 69 \\
\hline 6 & $50-60$ & 10 & 16 & 26 & 03 & 18 & 21 & 01 & 08 & 09 & 04 & 04 & 08 & 64 \\
\hline 7 & $60-70$ & 07 & 09 & 16 & 07 & 21 & 28 & 00 & 12 & 12 & 05 & 09 & 14 & 70 \\
\hline \multirow[t]{2}{*}{8} & $70-80$ & 00 & 02 & 02 & 03 & 05 & 08 & 00 & 04 & 04 & 03 & 05 & 08 & 22 \\
\hline & Total & 35 & 67 & 108 & 18 & 79 & 97 & 04 & 49 & 53 & 17 & 34 & 51 & 309 \\
\hline
\end{tabular}

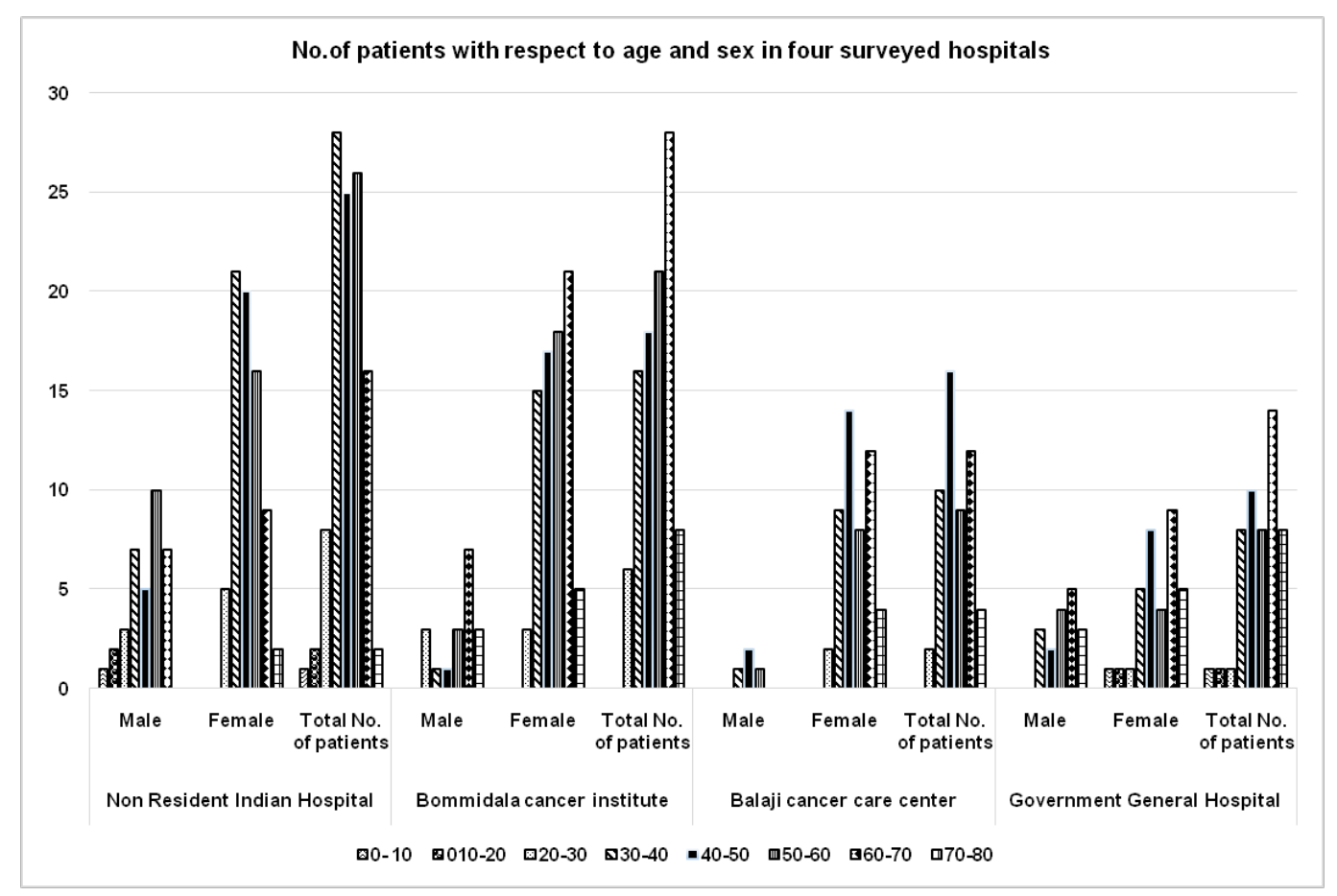

Fig. 2: Represents number of patients with respect to sex and age groups in all four hospitals 


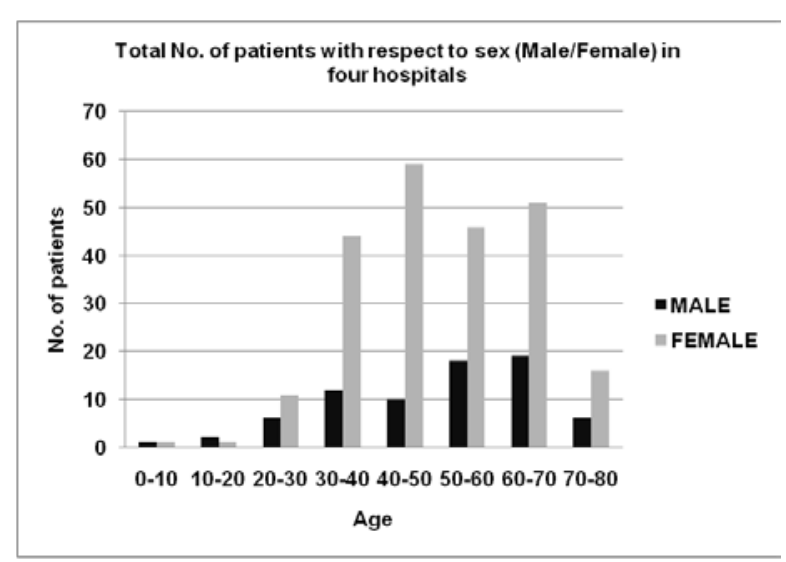

Fig. 3: Represents total number of patients with respect to age groups in all four hospitals in relation to sex

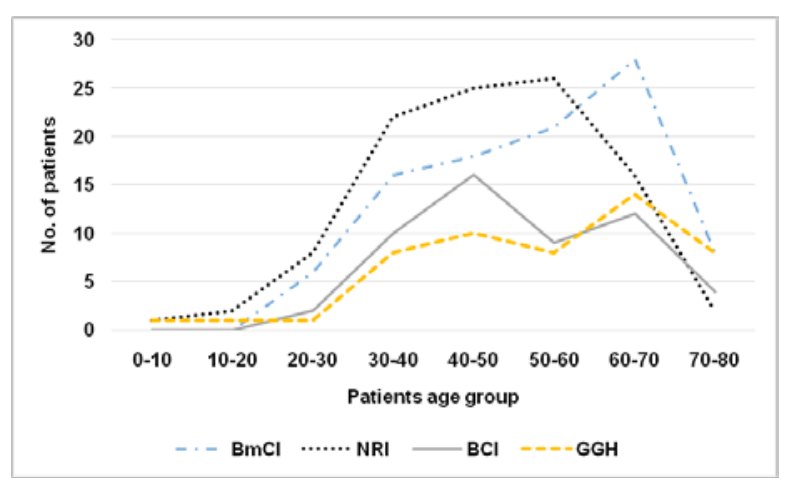

Fig. 4: Represents number of patients with respect to age in all four hospitals i.e. BMCI, NRI, BCC and GGH

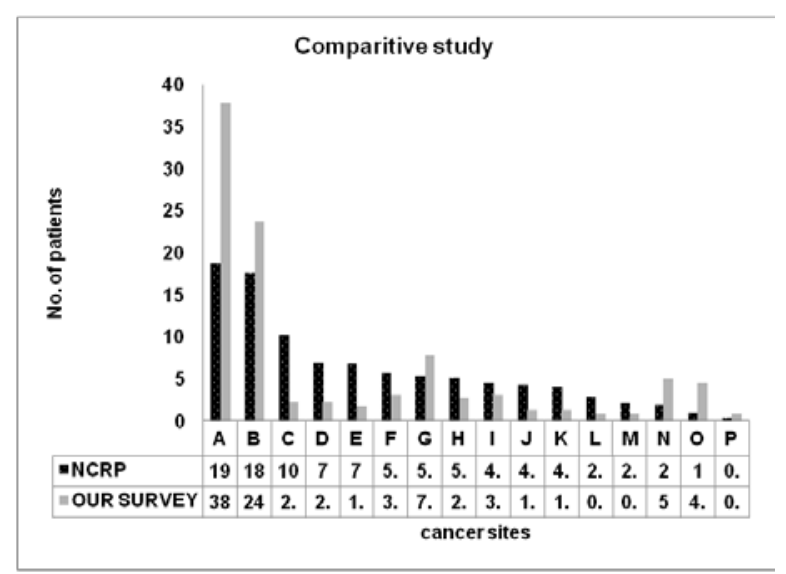

Fig. 5: Represents number of patients in relation to their cancer sites trough the survey with respect to NCRP data, A) Cervix Cancer B) Breast Cancer C) Ovary Cancer D) Lymphoid E) Leukemia F) Pharynx Cancer G) Endometrium Cancer H) Astrocytoma I) Tongue Cancer J) Colon Cancer K) Vault Cancer L) Larynx Cancer M) Rectum Cancer N) Lung Cancer 0) Oesophagus Cancer P) Post cricoid Cancer

\section{DISCUSSION}

Overall in four hospitals the major the number of patients were in the age of 60 to $70 \mathrm{y}$. The cancer attacks were more frequent in the age groups 30-70 y. In BMCI, BCI, GGH we found that the major numbers of patients are in the age between 60 to $70 \mathrm{y}$. While in NRI Hospital, we found the major numbers of patients are in age groups between 50 to $60 \mathrm{y}$. While in females, more number of cancer patients were in the age between 40 to $50 \mathrm{y}$. Our survey data results were compared to that of the National Cancer Registry Programme (NCRP) results. In NCRP results, the more number of patients were suffering with cervix cancer while our survey data also reveals that the more the number of patients were suffering with cervix cancer. The second major number of patients are suffering with breast cancer, which is same to that of the NCRP data and our survey data.

Most of the cancers have a common relationship with diet [16], among which oesophagus, stomach, colon and liver are predominant. Consumption of tobacco, alcohol, red chilies, and foods at high temperatures are the main risk factors for cancer. Avoidance of these products may reduce the risk of cancer occurrence. Among the cancer sites surveyed, cervical and breast cancers are more predominant and are widely seen in women. Female patient's outrage in cancer occurrence compared to male patients. More than $80 \%$ of cancers were identified in late stages, which made difficult to improve the quality life of patients and is the main reason for the poor survival from cancer in India [17]. A multidisciplinary approach to cancer treatment is essential, and this has to be made attainable at all district Regional cancer centers. The services of a trained surgeon along with supporting therapies and an essential drug list had to be made available at all centers [18].

There is, however, a possibility of under-registration of clinically diagnosed cases. Records may not be available for some of the patients in hospitals or clinics. Consequently, some of these might not be registered. The data collection is regularly supervised, and the information is carefully scrutinized. Evaluation of the survey has been undertaken with reliable data regarding the incidence of a type of cancers. To start with hospital-based cancer registries can be initiated by the regional cancer centers and they can be later expanded into population-based registries. The major cause of lung cancer is tobacco smoking [19]. It is important to initiate tobacco control measures if future increases in lung cancer burden are to be avoided. Cancer of the oesophagus showed a similar risk in both sexes. Nutritional deficiency probably contributes to the increased risk in females. Chewing of tobacco, smoking and alcohol seemed to contribute to a high risk in both sexes [20].

Breast cancer is the most frequent cancer of women, accounting for one-third of female cancers [21]. There are standard guidelines for estimating the cancer cases for most of the cancer sites [22]. Tobacco control measures are important to control and prevent an increase over the incidence of tobacco-related cancers. Cancer burden in females is high compared to men [23]. The survey deliberates that most of the cancer attacks were in the patient age groups between 40-70 y. Based on the hospital registry, it was found that the majority of cases were observed in females than the males. It was observed that due to lack of cancer education and that of particular disease awareness in the society [24]. The individuals fail in the identification of cancers in their early stages. So, in some cases, they have been motile and hence the study would deserve for the further investigation [25].

\section{CONCLUSION}

The cancer cases revealed by the study, in spite of the possible limitations of data quality, provide valuable information regarding about the control of cancer in the Guntur region. However, their applicability in our settings needs detailed studies and investigations. This seems particularly important for prostate, lung, rectum and colon cancers in men and for cervix, breast, ovary, and uterine cancers in women. Suitable methods of early detection linked with treatment should be considered in controlling this disease. It is important to develop hospital-based cancer registration in other representative regions of Guntur to allow better estimates of the pattern and the overall cancer burden. This will be useful in the overall context of planning and evaluation of cancer control activities in Guntur region.

\section{ACKNOWLEDGEMENT}

The authors are thankful for the support and cooperation provided by the staff of the four consecutive hospitals that helped us in gathering the information from the hospital registries. The support 
provided by prof A. Prameela rani, Principal, University College of pharmaceutical sciences, Acharya Nagarjuna University and Mr. D. Ravi sankar reddy, Department of pharmaceutical chemistry are gratefully acknowledged.

\section{CONFLICT OF INTERESTS}

The Authors declare that there is no conflict of interest for this article

\section{REFERENCES}

1. Takiar R, Nadayil D, Nandakumar A. Projections of a number of cancer cases in India (2010-2020) by cancer groups. Asian Pac J Cancer Prev 2010;11:1045-9.

2. Slygh L. Rediscovering biology: Molecular to global perspectives. Genomics Am Biol Teachnol 2005;67:120.

3. Nandakumar A, Anantha N, Venugopal TC, Sankaranarayanan R, Thimmasetty K, Dhar M. Survival in breast cancer: a population-based study in Bangalore, India. Int J Cancer 1995;60:593-6.

4. Murthy NS, Chaudhry K, Rath GK. The burden of cancer and projections for 2016, Indian scenario: gaps in the availability of radiotherapy treatment facilities. Asian Pac J Cancer Prev 2008;9:671-7.

5. Nandakumar A, Gupta PC, Gangadharan P, Visweswara RN, Parkin DM. Geographic pathology revisited: development of an atlas of cancer in India. Int J Cancer 2005;116:740-54.

6. Gopalakrishnan S, Umadevi R. An epidemiological analysis of cancer patients admitted to hospitals in Chennai, Tamil Nadu. Int J 2015;2:3.

7. Bland KI, Menck HR, ScottConner CE, Morrow M, Winchester DJ, Winchester DP. The national cancer data base 10-year survey of breast carcinoma treatment at hospitals in the United States. Cancer 1998;83:1262-73.

8. Arun S, Balachandar V, Sasikala K, Subramanian A, Abilash VG. Comparative and cross-sectional study of successes of the leprosy elimination strategy before (2000 to 2005) and after (2006 to 2010) eradication period in referral hospital of tamil nadu. Asian J Pharm Clin Res 2013;6:182-5.

9. Last JM. The iceberg: 'completing the clinical picture' in general practice. Int J Epidemiol 2013;42:1608-13.

10. Lekshmi S, Mohanta GP, Revikumar KG, Manna PK. Developments and emerging issues in public and private health care systems of kerala. Int J Pharm Pharm Sci 2014;6:92-8.

11. National Cancer Registry Program: Bangalore, (NCRP). Threeyear report of population-based cancer registries; 2009-2011.
12. Nandakumar, T Ramnath, Meesha Chaturvedi. The magnitude of cancer cervix in India. Indian J Med Res 2009;130:219-21.

13. National cancer Registry Programme (ICMR). Two-year report of the population-based cancer registries; 2004-2005.

14. Hospital-based Cancer registry Introduction. Available from: www.icmr.nic.in. [Last accessed on 02 Oct 2016]

15. Mehrotra R, Pandya S, Singhla M, Srivastava D, Singh M. Spectrum of malignancies in Allahabad, North India: a hospitalbased study. Asian Pac J Cancer Prev 2008;9:525-8.

16. Saka S, Singh AN, Sharma N. Potential anti-cancer superfoods: a mini review. Int J Curr Pharm Res 2016;8:19-21.

17. Takiar R, Nadayil D, Nandakumar A. Projections of a number of cancer cases in India (2010-2020) by cancer groups. Asian J Pharm Clin Res 2010;11:1045-9.

18. Pingili R. A prospective study on the assessment of risk factors for type 2 diabetes mellitus in outpatients department of a south Indian tertiary care hospital: a case-control study. Asian J Pharm Clin Res 2016;9:300-4.

19. Boffetta P, Hecht S, Gray N, Gupta P. Straif K. Smokeless tobacco and cancer. Lancet Oncol 2008;9:667-75.

20. Bhurgri Y, Bhurgri A, Hassan SH, Zaidi SH, Rahim A Sankaranarayanan $\mathrm{R}$, et al. Cancer incidence in Karachi, Pakistan: first results from Karachi cancer registry. Int J Cancer 2000;85:325-9.

21. Nandakumar A, Anantha N, Venugopal TC, Sankaranarayanan $\mathrm{R}$, Thimmasetty K, Dhar M. Survival in breast cancer a population-based study in Bangalore, India. Int J Cancer 1995;60:593-6.

22. Dikshit R, Gupta PC, Ramasundarahettige C, Gajalakshmi V, Aleksandrowicz L, Badwe R, et al. Cancer mortality in India: a nationally representative survey. Lancet 2012;60:1807-16.

23. Agarwal SP, Rao YN, Gupta S. Emerging strategies for cancer control in women of India; "Fifty years of cancer control in India". National cancer registry Programme; 2002. P. 48-59.

24. Ali I, Wani WA, Saleem K. Cancer scenario in India with future perspectives. Cancer Ther 2011;8:56-70.

25. Ruiz A, Facio Á. Hospital-based cancer registry: a tool for patient care, management and quality. A focus on its use for quality assessment. Rev Oncol 2004;6:104-13.

\section{How to cite this article}

- D Ravi Sankar Reddy, G Kalyani, K Pradeep, Md Asif, D Kartheek, M Gangabhavani. The survey of cancer patients in the region of guntur: based on hospital registry. Int J Pharm Pharm Sci 2017;9(2):228-232. 